\title{
Artificial Intelligent Machine Learning and Big Data Mining of Desert Geothermal Heat Pump: Analysis, Design and Control
}

\author{
Murad Al Shibli, Associate Professor \\ Head of Artificial Intelligent and Autonomous Systems Engineering Technology Program, \\ Project Manager of Joint Aviation Command (JAC) Program, \\ Abu Dhabi Polytechnic, IAT, Abu Dhabi, UAE \\ E-mail: murad.alshibli@adpoly.ac.ae \\ Bobby Mathew, Assistant Professor \\ Mechanical Engineering Department, College of Engineering, United Arab Emirates University (UAEU) \\ E-mail: bmathew@uaeu.ac.ae
}

Received: 15 October 2018; Accepted: 13 February 2019; Published: 08 April 2019

\begin{abstract}
Nowadays sustainable underground geothermal energy resources have received special attention thanks for being characterized as clean, zerocarbon footprint, reliable, and free source of renewable energy that can run all year long and around the clock. Barren desert lands, which make up 33\% and contribute to almost 30 Million $\mathrm{km}^{2}$ of global land surface area, is increasingly seen as supply of green energy but not yet efficiently and globally utilized although it can save up to $70 \%$ compared to traditional HVAC systems bills. This paper presents a novel artificial intelligent machine learning and big data algorithm to analyze and control geothermal heat pump system (GHP). In particular, the main objective of this research is to model, design, analyze, control and optimize the performance of desert underground GTH system based on thermodynamics laws and AI machine learning. As a case study, the analysis and design of desert GHP is performed based on the annual weather data collected for Al Ain city in UAE. By selecting a horizontal layout, the design analysis results show that GHP unit needs a $66 \mathrm{~m}$ total trench length with a cooling capacity estimated of $12.4 \mathrm{~kW}$, heat pump COP of 2.8 and 1.6 for the system COP with $30.3 \mathrm{~L} / \mathrm{min}$ water flow rate. Similar results for the heating system are obtained as well. Furthermore, financial calculations show the GHP system is very economic and competitive comparing with the traditional cooling/heating systems. It is figured out that the annual cost of the GHP system costs around $\$ 1676$ compared with $\$ 7992$ if air-cooled chiller and boiler are used. To maintain the geothermal system for one life cycle (usually 20 years) it needs to spend only $\$ 14,659$ compared with $\$ 109,944$ in case HVAC system is utilized. The overall life cycle cost in case of the desert GHP system does not exceed (45\%) of the traditional HVAC system $(\$ 81,881$ compared to $\$ 181,974)$. One of the direct applications is use this proposed desert GHP to cool the roof water tank for domestic and personal usage. Furthermore, artificial
\end{abstract}

intelligent and big data machine learning is executed to analyze the weather conditions related to the GHP performance based on huge number of thermal observations recorded for the years 2015-2018. Moreover the mean switch-off control hours of the GHP is examined by developing a supervised learning predictive model. For the purpose of validation a four ton Bosch GHP unit is selected as a benchmark. Switch-off control hours per month for the entire geothermal data set are demonstrated by using a linear regression model that help to guide the controller to switch-on/switch-off the system without having the need for the real data measurement. One primary outcome obtained is the ability to optimize the GHP performance, save primary input energy and operation periods. Furthermore, the results interprets that almost one third of the year is in a switched-off saving mode $(33 \%)$, compared to $67 \%$ in switch-on mode. This smart big data control will lead to a life-cycle saving of $\$ 27,020$. This AI saving strategy is found to be competitive and leading compared to other schemes. It is worthy to recommend linking GHP controller with realtime radar or weather station that will fed the system with real data conditions which would lead to improving its performance and dispense costly measuring sensors.

Index Terms-Artificial intelligent systems, big data, machine learning, geothermal heat pump, domestic cooling system, switch-on-switch-off control.

\section{INTRODUCTION}

\section{A. Geothermal Heat Pumps System Review}

Geothermal heating and cooling system generates its energy to cool or heat residential and commercial building by utilization of the comparatively fixed temperature of earth saving $40 \%$ to $70 \%$ energy compared to the traditional heating and cooling systems 
(HVAC). Although traditional HVAC systems use fuel to produce heat, geothermal heat pumps (GHP) use electrical power to basically remove heat from the soil into houses, resulting in much more thermal efficiencies. Fuel-based burning heaters efficiency can reach up to $95 \%$, compared to more than $400 \%$ actual equivalent efficiency when applying geothermal heat pumps due to removing up to 4 units of heat load for one single electrical power unit required to operate the system.

A fundamental feature of earth-based source geothermal heat pump uses soil or underground water as the input source of heat in winter and cold seasons, meanwhile it becomes oppositely the sink to extract heat from homes in summer and hot seasons as depicted in Fig. 1. This is basically is implemented through a heating cycle of the geothermal heat pump system by using a serial pipes network loop to remove heat from earth. As a result warm air can be supplied to residential closed areas through an air duct circuits. Similarly, the heat source can be used to heat-up water supply as well as warming up domestic floor layouts. In the contrary, in summer seasons the cooling system of the same geothermal heat pumps systems can be activated by reversing the heat loop to supply air-conditioned spaces. Air-conditioning mode of geothermal systems can be operated by removing the heat indoor spaces and rejecting it back into the ground series piping loop to heating domestic water supply. As a result of such a reversal thermal process, cooled air is provided to through the air ducting system.

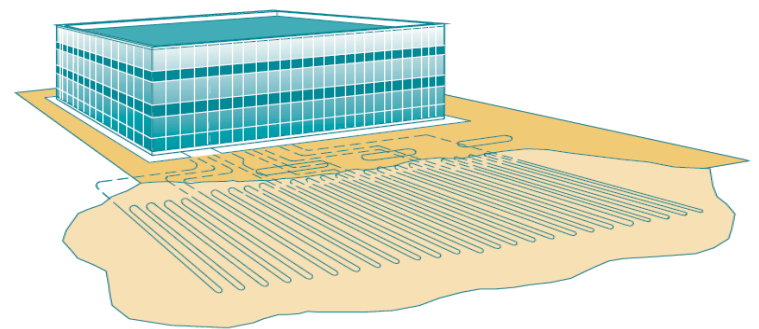

Fig.1. Geothermal Heat Pump Horizontal Layout

It is reported that the world total electrical energy was 13,267 billion $\mathrm{kWh}$ in 1995 [1]. Only $0.4 \%$ of this world total electrical energy ( 38 billion $\mathrm{kW}$ ) was generated by geothermal electrical representing global installed capacity of $7173.5 \mathrm{MW}$ as per 1996. Geothermal kWh output is economically efficient ranges between 3-12 US cents/kWh compared to traditional energy resources.

Geothermal heat pumps (GHP) works at ground temperatures conditions which is slightly above 50 to 90 F [2]. GHP has an advantage of consuming less annual energy up to $33 \%$ and requires simpler design and maintenance. Although it needs more initial investment capital, but the annual operating cost will lead to reasonable net savings and lower overall life expenses. These savings results from the water-ground GHP average coefficient of performance (COP) of 3 compared to 2 in the case where air-source heat pumps are used.

Geothermal domestic resources represents 30,000-year energy supply assuming similar rate in USA but geothermal energy utilization has not reached its optimum in terms of clean and secure energy [3]. USA as the global giant geothermal producer of electricity generates around of 15 billion kilowatt hours of power per year [4]. Unlike other renewable geothermal resources can be utilized all year long and 7 days a week. It is reported that a combination 9 western states have the potential to generate around $20 \%$ of US electrical power needs.

It is figured out that geothermal fields may produce only $15 \%$ of $\mathrm{CO} 2$ compared to traditional natural gas power plants [5]. Geothermal electrical plants can generate about $20 \%$ of the total electricity needs consumed in California. In is identified that in 10 western states there are more than 9,000 thermal wells and springs with many small businesses opportunities [6]. It is reported that California State represents almost $66 \%$ of the geothermal electrical power capacity that hits around 3,000 MW with additional potential to reach 5,000 to 13,000 MW [7].

In Geothermal systems there is a huge water pressure drop in the ground loop that needs a high pumping power [8]. It is practical when having a water source heat pump systems to have a similar or higher COP compared to most complicated air systems. Economic data and U.S. geothermal policy are illustrated in [9] a clean energy generation. A model has been developed in order to simulate an air conditioning system with geothermal heat pump in the research work [11].

A ground source heat pump (GSHP) uses the shallow ground as a source of heat, thus taking advantage of its seasonally moderate temperatures. The model leads to design optimization of geothermal heat exchangers and to verify the operation of the geothermal plant. The research paper [12] presents the step-by-step for estimate, design, calculation, procurement, installation and commissioning of geothermal heating and air conditioning system for residential or small businesses. A comparison between the conventional HVAC and the geothermal counterpart is provided to demonstrate their advantages.

The geothermal air conditioning, including a brief description of the Geothermal cooling system with additional system of evaporative cooling coils has been incorporated in the project work [13]. This description is empowered with the experimental analysis of the system and the heat transfer calculations. The hybrid renewable systems work [14] aims to model, simulate and analyze the performance of FL based PVT integrated GSHP system for typical residential buildings. For the GSHP system, the advanced FL control results in approximately $9.5 \%$ primary energy saving in the heating period, $12.7 \%$ in the shoulder heating period and $18.3 \%$ in the cooling period, $17.4 \%$ in the cooling shoulder period and $12 \%$ annually compared to the On-Off control strategy.

Air-conditioning of the space in an economic way to save electricity was presented in [15]. Effective use of heat exchanger is shown through computation, modelling schemes and lab experiment. It is observed that the ambient air temperature of $35^{\circ} \mathrm{C}-40^{\circ} \mathrm{C}$ in the room can be brought down to $26^{\circ} \mathrm{C}$ without much consumption of electricity. The study survey in [16] indicates the use of 
earth as a heat-sink with an aim of controlling global warming and moving towards a greener air-conditioning technology.

Integrated systems of solar and geothermal energies and proposes design for heating, ventilation and air cooling system for use in Gujarat on commercial basis for domestic and commercial buildings is discussed in the work [17]. The results prove economical than conventional cooling systems working on electrical energy as it makes use of both the accumulation and loss of heat simultaneously at two different places for heating and cooling respectively. A general description of passive cooling system of building by using ground as a heat exchanger is given in [18]. This project utilizes less area and results in more fruitful outcomes with respect to passive cooling.

\section{B. Related Work Review}

A review of the recent advancements in geothermal heating and cooling system is presented by the work [19]. It uses earth's heat for space heating and cooling with the use of heat pump systems, saving up to $51 \%$ electricity consumption in HVAC, and reduced $\mathrm{CO} 2$ emissions. A description of the Geothermal cooling system is included in the paper [20]. It demonstrates the experimental analysis of the system and the heat transfer calculations. Sustainable renewable heating system for residential buildings and domestic hot water is proposed in [21] based on a combined solar ground heat pump system.

Modeling and operation control is implemented using TRNSYS software. A maximum COP of 3.75 is reported with power reduction of $8.7 \%$. Two pilot systems have been created to upgrade the heating/cooling systems of two existing buildings on the largest industrial estate in Italy are reported in [22]. The first system features a geothermal heat pump with an innovative layout: a heatstorage water tank, buried just below ground level, allows a significant reduction of the geothermal unit size, hence requiring fewer and/or shorter boreholes (up to $60 \%-$ $70 \%)$.

Machine learning challenges with Big Data were compiled, summarized, and organized in paper [23]. The article [24] unfolds a uniform model to facilitate the exploitation of the experiences produced by the interactions of the pedagogical actors. A comprehensive survey on what is Big Data, comparing methods, its research problems, and trends was provided in [25]. Then a survey of Deep Learning, its methods, comparison of frameworks, and algorithms is presented. An extensive literature study and review of latest advances and new methodologies in researches on machine learning for processing big data is presented in [26].

A literature survey of the latest advances in researches on machine learning for big data processing is presented in [27]. It reviews the machine learning techniques and highlight some promising learning methods in recent studies, such as representation learning and deep learning. In the article proposed in [28] to use general machine learning approach by finding that memory mapping is also a feasible technique for scaling up general machine learning algorithms that enables existing machine learning algorithms to work with out-of-core datasets through memory mapping a faster speed. A survey of latest optimization methods for big data applications is presented in [29]. Revision of data mining algorithms used for CRM is presented in review paper [30].

Prediction of Greenland geothermal heat flux is investigated using machine learning in the article [31]. This work aims to model and understand heat stemming underground Greenland Ice Sheet and predict ice losses and rise of sea water. A prediction model of energy demand using machine learning and linear regression is presented in [32]. This work aimed to determine the thermal response time of the building. It is found that the response time is almost $40 \mathrm{~min}$. Hot water consumption patterns of air-to-water heat pump and associated COP are trained using support vector machines (SVM) [33]. The operation analysis over one year is evaluated to predict COP in comparison to the actual value.

Bosch Applications Manual presents some of the most common applications of Bosch geothermal heat pumps for residential applications [34]. This applications manual provides a complete review of geothermal heat pump technology, components and operation, as well as guidance on the design and installation of ground heat exchangers and Bosch geothermal heat pump systems for domestic use (residential).

This paper present a novel approach to control the operation of GTP system using artificial intelligent machine learning and thermal big data. This paper is organized as follows. Section II on 'Geothermal Heat Pump Loop Classifications and Advantages' identifies different types of geothermal heat pumps, while Section III 'Heat Pump Thermodynamics' introduces the thermodynamics principles of heat pump is discussed in Section III. A geothermal case study for Al-Ain city in United Arab Emirates is considered in the section IV 'Geothermal Heat Pump Design: United Arab Emirates Outlook Case'. In section V, Artificial Intelligent and Big Data Machine Algorithm is presented. Meanwhile, learning of Desert Geothermal Heat Pump. Furthermore, the application of AI and Big Data Machine learning to control geothermal heat pump in UAE is introduced in section VI. Finally, conclusions and future work are discussed in section VII.

\section{Geothermal HeAt Pump LoOP ClassificAtions AND ADVANTAGES}

\section{A. GHP Classifications}

Geothermal heat pumps systems can basically be classified into two major groups: closed-loop and closedloop systems. The closed-loop is made-up of series of piping circuit buried underground or submerged in the water. Meanwhile, open-loop type is based on pumping underground water. The selection of the loop type is particularly depends on the expense of soil drilling or trenching, the nature of ground topography, the availability heat source such as ground, water or air. 
Classification of these GHP loops are displayed in Fig.2:

- Horizontal Trench Loop Type;

- Vertical Loop Type;

- $\quad$ Pond Loop Type;

- $\quad$ Open Loop Type;

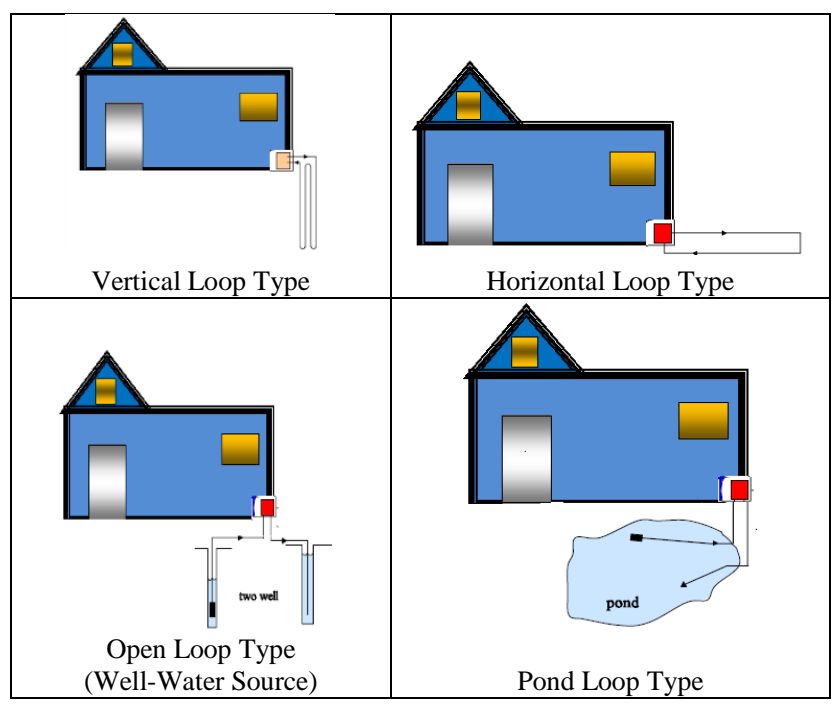

Fig.2. Geothermal Heat Pump Types

\section{B. GHP Advantages}

GHP known as water-and-ground-coupled heat pumps are more advantageous over air-source heat pumps as follows:

- Low Operating Cost: GHP are characterized by delivering 4 units of energy as output compared to one single unit input of electrical energy. This is equivalent to $400 \%$ efficiency rating comparing to 945 of gas burning systems.

- Superior Comfort and Safer.

- Cleaner and Quieter.

- Reliable and Environmentally Friendly.

The following figures represents saving energy and costs of GHP compared heating sources and applications.

Table 1. Heat Sources Comparison in terms of Heat Value and Annual Cost*

\begin{tabular}{|c|c|c|c|c|c|}
\hline $\begin{array}{c}\text { Energy/Fuel } \\
\text { Source }\end{array}$ & $\begin{array}{c}\text { Heat } \\
\text { value in } \\
\text { Btu }\end{array}$ & Units & Cost / Unit & $\begin{array}{c}\text { Cost } \\
1,000,00 \\
0 \mathrm{Btu}\end{array}$ & $\begin{array}{c}\text { Approx. } \\
\text { Annual } \\
\text { Cost }\end{array}$ \\
\hline Propane & 24,197 & Liter & $\$ 0.885 /$ liter & $\$ 47.55$ & $\$ 4,755.00$ \\
\hline Oil & 36,596 & Liter & $\$ 1.00 /$ liter & $\$ 38.26$ & $\$ 3,826.00$ \\
\hline Electricity & 3,413 & $\mathrm{kWh}$ & $\$ 0.08 / \mathrm{kW}$ & $\$ 23.44$ & $\$ 2,344.00$ \\
\hline Natural Gas & 948,213 & $\mathrm{GJ}$ & $\$ 16.00 / \mathrm{GJ}$ & $\$ 21.94$ & $\$ 2,194.00$ \\
\hline $\begin{array}{c}\text { Air Source } \\
\text { Heat Pump }\end{array}$ & 3,413 & $\mathrm{kWh}$ & $\$ .08 / \mathrm{kW}$ & $\$ 9.38$ & $\$ 938.00$ \\
\hline $\begin{array}{c}\text { Ground } \\
\text { Source Heat } \\
\text { Pump }\end{array}$ & 3,413 & $\mathrm{kWh}$ & $\$ .08 / \mathrm{kW}$ & $\$ 4.68$ & $\$ 468.00$ \\
\hline $\begin{array}{l}* \text { February 2007 for Victoria, BC, based on a home of approximately } \\
\text { 2,000 square feet, \$CAD }\end{array}$ & & & & \\
\hline
\end{tabular}

Copyright @ 2019 MECS

\section{HEAT PUMP THERMODYNAMICS}

Heat pump unit is a device can be defined as thermal system that that extracts heat energy from a cold medium to a warm medium as displayed in Fig. 3. It worth to mention that both GHP and Refrigerators share the same cycle but are different in purposes. The main purpose of a refrigeration unit is to keep the cooled space at a low temperatures by extracting heat from it and discharging it to a warm medium.

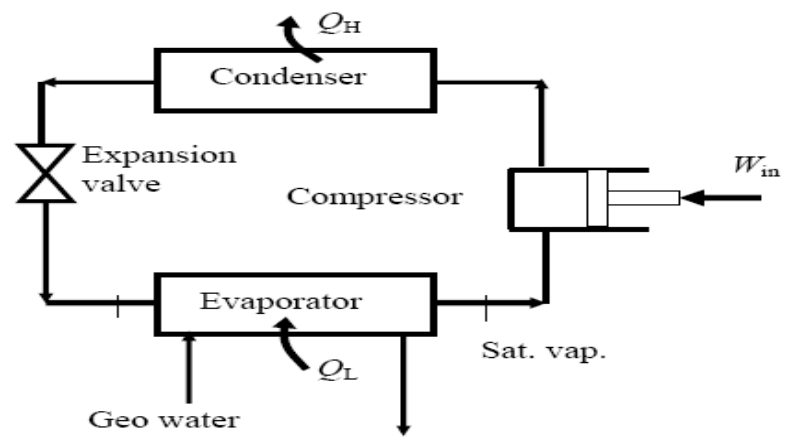

Fig.3. Heat Pump Schematic Diagram

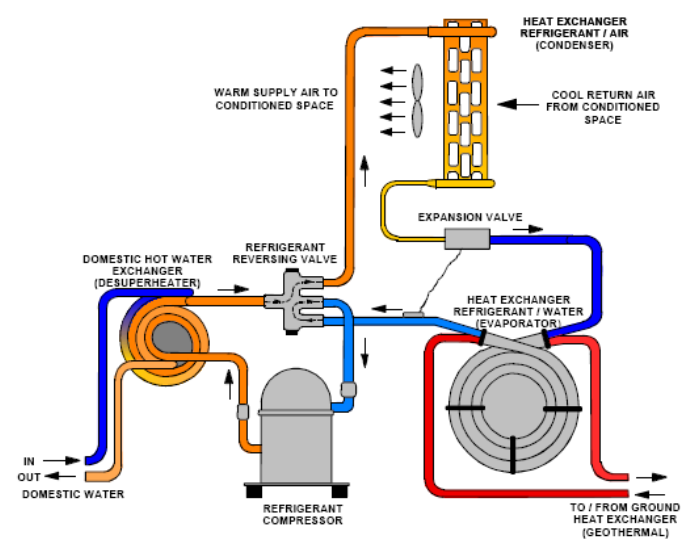

Fig.4. Geothermal Heat Pump Type (Source: Oklahoma State University)

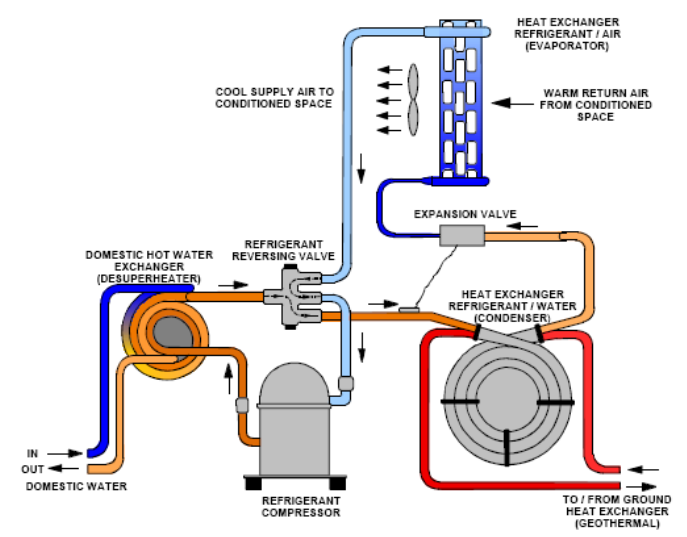

Fig.5. Geothermal Cooling Pump Type (Source: Oklahoma State University)

On the other hand, the purpose of a GHP is meant to ensure the heated space is kept at a high temperature conditions. This can be achieved by extracting heat from a low-temperature medium (well water or outdoor air) 
and providing it to the high-temperature space (indoor home). Fig. 4 and Fig. 5 demonstrate the schematics of the geothermal heat pump and cooling pump, respectively.

For the purpose of analysis a steady-flow process is assumed, the heat-pump thermodynamics is governed by four balance equations, balance of mass, balance of energy, balance of exergy and finally balance of entropy . These balance equations are applied to find the heat input, the rate of exergy decrease, the rate of irreversibility, and the energy and exergy efficiencies [10]. These relations reinforce the fundamental principles that during an actual process mass and energy are conserved, entropy is generated, and exergy is destroyed.

The mass balance equation can be expressed in the time rate of change form

$$
\dot{m}_{\text {in }}-\dot{m}_{\text {out }}=\frac{d m_{\text {sys }}}{d t}=0
$$

where $\dot{m}$ is the mass flow rate, and the subscript in and out stands for inlet and out for outlet, respectively, meanwhile $\frac{d m_{s y s}}{d t}$ represents the rate of change in mass accumulated in the system. The general energy $E$ balance can be formulated as:

$$
\dot{E}_{\text {in }}-\dot{E}_{\text {out }}=\frac{d E_{\text {sys }}}{d t}=0
$$

where $E$ stands for Energy, the subscript in and out stands for inlet and out for outlet, respectively. Meanwhile, the general energy balance can be specified more explicitly as

$$
\left(\dot{Q}_{\text {in }}-\dot{Q}_{\text {out }}\right)+\left(\dot{m}_{\text {in }} h_{\text {in }}-\dot{m}_{\text {out }} h_{\text {out }}\right)=\left(\dot{W}_{\text {out }}-\dot{W}_{\text {in }}\right)
$$

where $Q$ stands for the heat, $\left(\dot{Q}_{\text {in }}-\dot{Q}_{\text {out }}\right)$ is the rate of net heat output, $W$ stands for the work, $\left(\dot{W}_{\text {out }}-\dot{W}_{\text {in }}\right)$ is the rate of net of work output, and $h$ is the enthalpy per unit mass. The rate form of the balance of entropy $S$ is given by:

$$
\left(\dot{S}_{\text {in }}-\dot{S}_{\text {out }}\right)+\dot{S}_{\text {gen }}=\frac{d S_{\text {sys }}}{d t}=0
$$

where $\left(\dot{S}_{\text {in }}-\dot{S}_{\text {out }}\right)$ stands for the net of entropy inputoutput, $S_{g e n}$ is the generated entropy. Moreover, the rates of entropy transfer by heat transferred at a rate of $\dot{Q}_{i n}$ and mass flowing at a rate of $\dot{m}$ are defied as $\frac{d S_{\text {heat }}}{d t}=\frac{\dot{Q}_{i n}}{T_{i n}}$ and $\frac{d S_{\text {mass }}}{d t}=\dot{m} s$, respectively. The last Equation (4) can be modified as:

$$
\dot{S}_{\text {gen }}=\dot{m}_{\text {out }} s_{\text {out }}-\dot{m}_{\text {in }} s_{\text {in }}-\frac{\dot{Q}_{\text {in }}}{T_{\text {in }}}
$$

Moreover, the general exergy balance $X$ can be expressed in the rate form as:

$$
\left(\dot{X}_{\text {in }}-\dot{X}_{\text {out }}\right)+\dot{X}_{\text {dest }}=\frac{d X_{s y s}}{d t}=0
$$

where $\left(\dot{X}_{\text {in }}-\dot{X}_{\text {out }}\right)$ stands for the net of general exergy balance, and $\dot{X}_{\text {dest }}$ is the net of the destroyed energy (energy destruction). The rate form of the general exergy balance can now be written as:

$$
\left(1-\frac{T_{0}}{T}\right)\left(\dot{Q}_{\text {in }}-\dot{Q}_{\text {out }}\right)-\left(\dot{W}_{\text {out }}-\dot{W}_{\text {in }}\right)+\left(\dot{m}_{\text {in }} \phi_{\text {in }}-\dot{m}_{\text {out }} \phi_{\text {out }}\right)=\dot{X}_{\text {dest }}
$$

where $T_{0}$ refers to the environment temperature, $T$ stands for the medium temperature, $\phi=\left(h-h_{0}\right)-T_{0}\left(s-s_{0}\right)$ is defined as the flow (specific) exergy. The irreversibility $I$ is given by the following equation:

$$
\dot{I}=T_{0} \dot{S}_{g e n}
$$

Furthermore, the coefficient of performance of energy of the geothermal heat pump unit itself $C O P_{\text {heat-pump }}$ and, meanwhile, the whole system $C O P_{s y s}$ can be determined, respectively, by

$$
C O P_{\text {heat }- \text { pump }}=\frac{\dot{Q}_{\text {shl }}}{\dot{W}_{\text {comp }}}
$$

$$
C O P_{s y s}=\frac{\dot{Q}_{\text {shl }}}{\dot{W}_{\text {input }}}
$$

where $\dot{Q}_{\text {shl }}$ the space heating load, $\dot{W}_{\text {comp }}$ is the work input to the compressor and $\dot{W}_{\text {input }}$ is the total work input rate to the system.

\section{Geothermal HeAt Pump Design: United ARAB EMIRATES CASE STUDY}

\section{A. Thermal Conditions}

Desert is increasingly seen as sources for solar energy. The technology now exists to supply all of the world's electricity needs with $10 \%$ of the Sahara. Mojave Solar Park will be the world's largest solar generating plant. Sand covers only about $20 \%$ of Earth's deserts as listed in Table 2. Remarkably, the total desert areas on Earth is almost close to $29,800,000 \mathrm{~km}^{2}$ which represent a 
sustainable and free source of renewable energy. Sahara and Middle East deserts only represents $30 \%$ and $10 \%$ of this geothermal source, respectively. The global energy map details the solar energy per unit area is shown in Fig. 6. It can be noticed that the maximum solar exposure exist in Sahara desert in Africa and Arabian Desert in the Middle East. Fig. 7 shows an amazing photo of one site of Al-Ain desert.

Table 2. Global Largest Deserts Area (Total: 29,788,430 km²)

\begin{tabular}{|r|c|c|}
\hline \hline \multirow{2}{*}{ Rank } & Desert & Area $\left(\mathrm{km}^{2}\right)$ \\
\hline \hline 1 & Antarctic Desert (Antarctica) & $13,829,430$ \\
\hline 2 & Sahara (Africa) & $9,100,000$ \\
\hline \hline 3 & Arabian Desert (Middle East) & $2,330,000$ \\
\hline \hline 4 & Gobi Desert (Asia) & $1,300,000$ \\
\hline \hline 5 & Kalahari Desert (Africa) & 900,000 \\
\hline \hline 6 & Patagonian Desert (South America) & 670,000 \\
\hline \hline 7 & Great Victoria Desert (Australia) & 647,000 \\
\hline \hline 8 & Syrian Desert (Middle East) & 520,000 \\
\hline \hline 9 & Great Basin Desert (North America) & 492,000 \\
\hline \hline & Total & $29,788,430$ \\
\hline \hline
\end{tabular}

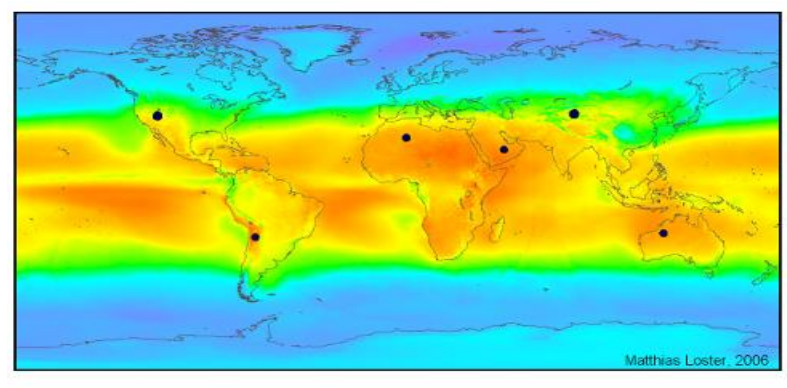

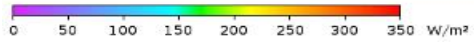

Fig.6. Global Solar Heat Energy Map per Unit Area

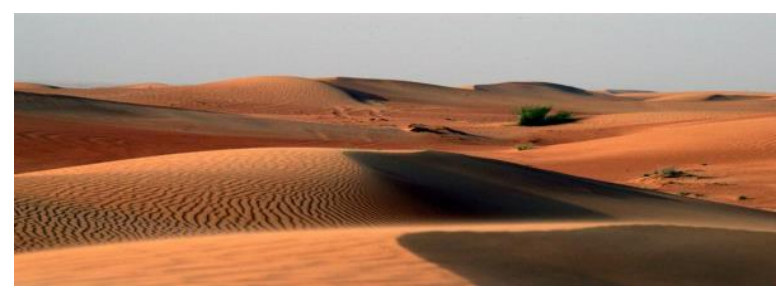

Fig.7. A Photo of an Open UAE Desert Outlook

Table 3. Monthly Air Temperature, Soil Temperature and Solar Radiation (Al-Ain City, UAE )

\begin{tabular}{|c|c|c|c|c|c|c|c|}
\hline \multirow{3}{*}{$\begin{array}{l}\text { Month } \\
\text { الثهر }\end{array}$} & \multicolumn{3}{|c|}{ Temperature $\left({ }^{\circ} \mathrm{C}\right)$} & \multicolumn{3}{|c|}{ Soil $\left({ }^{\circ} \mathrm{c}\right)$} & \multirow{2}{*}{$\begin{array}{c}\begin{array}{c}\text { Solar Radiation } \\
\text { (Wh/m2) }\end{array} \\
\text { الإشعاع الثمسي }\end{array}$} \\
\hline & \multicolumn{3}{|c|}{ درجة الحرارة } & \multicolumn{3}{|c|}{ درجة حرارة التربة } & \\
\hline & Max. & Mean & Min. & Max. & Mean & Min. & Total \\
\hline Jan & 28.8 & 17.2 & 05.3 & 31.5 & 19.7 & 10.2 & 242664 \\
\hline Feb & 34.8 & 20.0 & 06.5 & 35.4 & 23.9 & 12.0 & 312211 \\
\hline Mar & 38.3 & 24.1 & 10.9 & 40.2 & 28.3 & 15.3 & 380966 \\
\hline Apr & 43.3 & 29.7 & 12.7 & 46.1 & 34.9 & 20.7 & 398018 \\
\hline May & 44.9 & 34.3 & 21.6 & 50.9 & 40.3 & 31.9 & 408292 \\
\hline Jun & 50.0 & 35.7 & 23.8 & 52.7 & 42.4 & 34.3 & 360983 \\
\hline Jul & 49.2 & 37.2 & 25.7 & 59.8 & 44.1 & 33.3 & 410121 \\
\hline Aug & 48.3 & 37.2 & 26.9 & 58.6 & 41.7 & 28.5 & 395657 \\
\hline Sep & 46.1 & 33.9 & 21.2 & 52.7 & 39.1 & 28.5 & 379552 \\
\hline Oct & 40.9 & 29.7 & 17.4 & 49.5 & 34.6 & 24.3 & 348244 \\
\hline Nov & 36.6 & 24.5 & 14.1 & 44.0 & 28.6 & 19.3 & 270829 \\
\hline Dec & 29.9 & 19.1 & 06.2 & 33.0 & 21.4 & 13.5 & 253926 \\
\hline
\end{tabular}

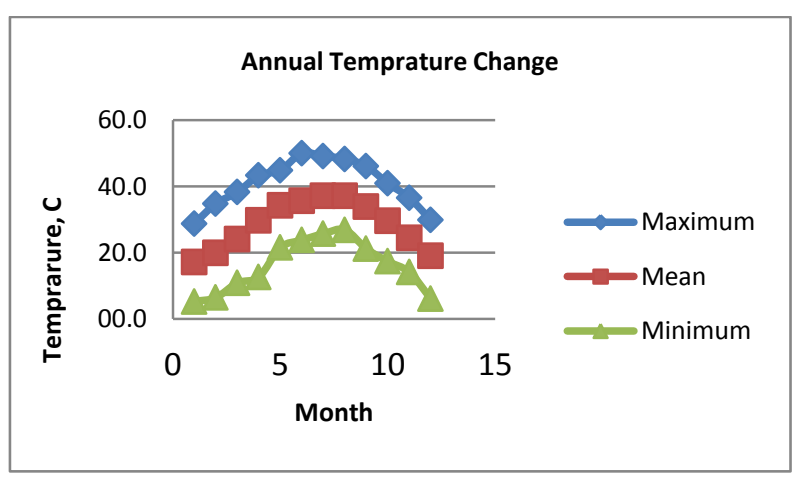

Fig.8. Annual Temperature Changes in Al-Ain, UAE

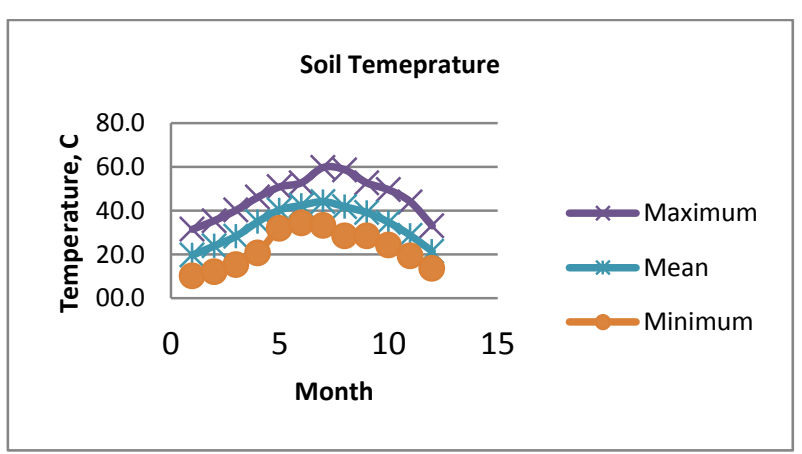

Fig.9. Desert Soil Temperature Changes in Al-Ain, UAE 


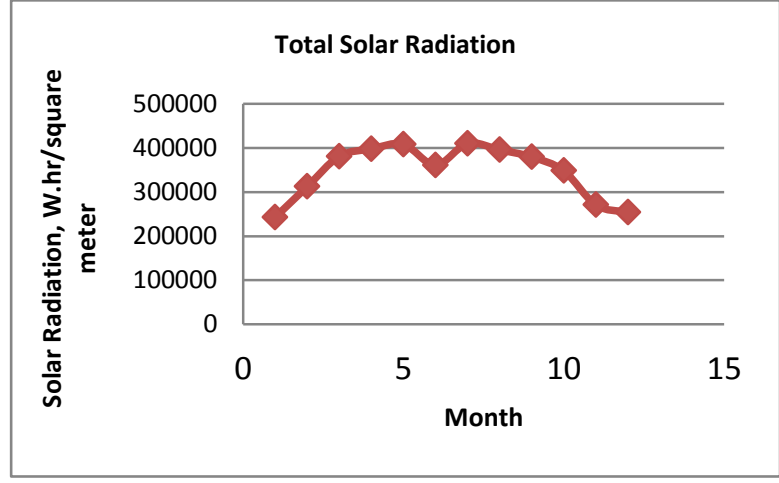

Fig.10. Total Solar Radiation in Al-Ain City in UAE

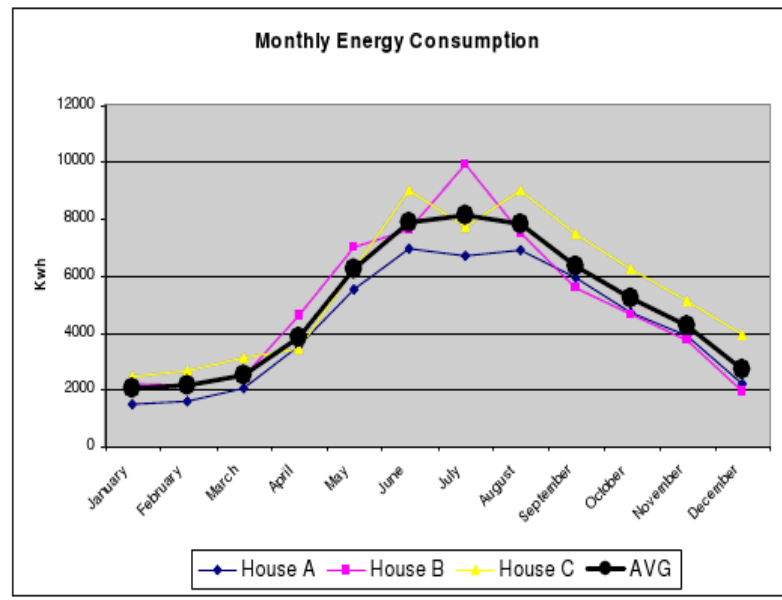

Fig.11. Cooling Load of an Average House in UAE

Details of the annual air temperature, soil temperature and solar radiation in Al-Ain City in United Arab Emirates are displayed in Table 3 and Fig. 8, 9 and 10. It can be seen that July records the highest temperature of $50^{\circ} \mathrm{C}$ along with $60^{\circ} \mathrm{C}$ for soil temperature and 410 $k \mathrm{~W} / \mathrm{m}^{2}$. Meanwhile, the temperature in winter nights may drop to $6^{\circ} \mathrm{C}$. The maximum and minimum monthly ambient average temperature ranges from $30-50^{\circ} \mathrm{C}$ and 6$25^{\circ} \mathrm{C}$, respectively as shown in Fig. 8. On the other hand, Fig. 9 displays that the highest and lowest monthly soil average temperature varies from $30-60^{\circ} \mathrm{C}$ and $10-35^{\circ} \mathrm{C}$, respectively. This indicates for a crucial need for a combined cooling system in the summer season and a heating system in the winter time. Soil embodies a huge source of free geothermal reservoir. This due to a high solar radiation that ranges from $220,000-400,000 \mathrm{Whr} /$ $m^{2}$ as depicted in Figure 10.

In general, geothermal heat pump are considered to be most economical in UAE and meeting entire cooling load where having a huge cooling load during summer season and a relatively small heating load during winter.

\section{B. Geothermal HeatPump: System Design}

Examining the average cooling load of houses in UAE indicates that a consumption of $8000 \mathrm{kWh}$ in the peak summer time and $2000 \mathrm{kWh}$ in the cool winter season as shown in Fig. 11. These data are used as a reference to design a geothermal cooling/heating pump system.
For this case study the following system specification have been selected: a) the pump has a power of $2 \mathrm{~kW} \&$ $85 \%$ efficiency, b) one inch pipe size is selected with turbulent flow, c) the average swing temperature is selected as $60^{\circ} \mathrm{C}$, d) water is selected to be the cooling fluid of the geothermal heat pump.

The design analysis results identify the need for 5 trenches such that they are 2 meter deep and that are separated from one another by 2 meters (2 meter separation from trench center to trench center). Two layers of double pipes will be placed in each trench. In each trench, the pipes will have a $30 \mathrm{~cm}$ horizontal separation and a $30 \mathrm{~cm}$ vertical separation. Each trench will be 12 inches wide as Design data are depicted in Fig. 12.

The overall geothermal analysis results are demonstrated in Table 4. The thermal analysis shows that the GHP unit requires a total trench length of $66 \mathrm{~m}$ associated with $132 \mathrm{~m}$ pipe length. The cooling capacity estimated is as $12.4 \mathrm{~kW}$ associated with a heat pump COP of 2.8 along with system COP of 1.6 and water flowrate of $30.3 \mathrm{~L} / \mathrm{min}$. Moreover, the heating load capacity is calculated as $14.8 \mathrm{~kW}$, heat pump COP of 4.3 and 2.3 system COP with a water flow rate up to $37.9 \mathrm{~L} / \mathrm{min}$. The predicted peak load for both cooling and heating are 9.4 and $11.7 \mathrm{~kW}$, respectively.

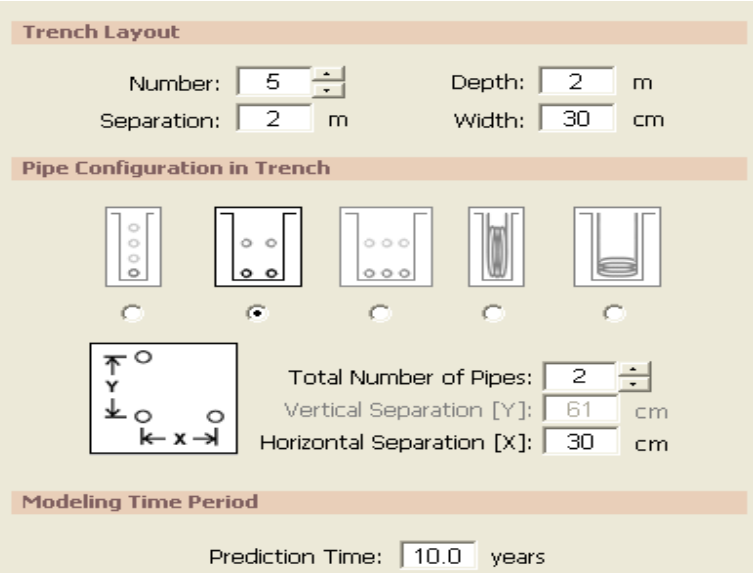

Fig.12. Trench System Layout

Table 4. Geothermal System Design Calculations Results

$\begin{array}{lll} & \text { COOLING } & \text { HEATING } \\ \text { Total Trench Length }(\mathrm{m}): & \mathbf{6 6 . 0} & 0.0 \\ \text { Trench Number: } & \mathbf{5} & 5 \\ \text { Single Trench Length }(\mathrm{m}): & \mathbf{1 3 . 2} & 0.0 \\ \text { Total Pipe Length }(\mathrm{m}): & \mathbf{1 3 1 . 9} & 0.0 \\ \text { Single Trench Pipe Length }(\mathrm{m}): & \mathbf{2 6 . 4} & 0.0 \\ \text { Unit Inlet }\left({ }^{\circ} \mathrm{C}\right): & \mathbf{2 9 . 4} & 10.0 \\ \text { Unit Outlet }\left({ }^{\circ} \mathrm{C}\right): & \mathbf{3 5 . 5} & 6.6 \\ \text { Total Unit Capacity }(\mathrm{kW}): & \mathbf{1 2 . 4} & \mathbf{1 4 . 8} \\ \text { Peak Load }(\mathrm{kW}): & \mathbf{9 . 4} & \mathbf{1 1 . 7} \\ \text { Peak Demand }(\mathrm{kW}): & \mathbf{5 . 7} & 5.1 \\ \text { Heat Pump COP: } & \mathbf{2 . 8} & 4.3 \\ \text { System COP: } & \mathbf{1 . 6} & 2.3 \\ \text { System Flow Rate }(\mathrm{L} / \mathrm{min}): & \mathbf{3 0 . 3} & 37.9\end{array}$

Furthermore, financial calculations show the geothermal system is very economic and competitive 
comparing with the traditional cooling/heating systems as shown in Table 5. It is found out that the annual cost of the geothermal system costs around $\$ 1676$ compared with $\$ 7992$ when air-cooled chiller and boiler are used. To maintain the geothermal system for a life cycle (usually 20 years) it needs only $\$ 14,659$ comparing with 109,944 for air-cooled chiller and boiler conventional system. The overall life cycle of the geothermal system does not exceed $(45 \%)$ of the life costs of the traditional system (\$81,881 compared to $\$ 181,974)$.

Another direct system application of the GHP in UAE is to use it to cool the roof water tank in summer time as shown in Fig. 13. The water temperature becomes very hot and cannot bear it for domestic and personal usage washing hands and body, taking showers, cleaning homes especially by kids, women and elder people. This proposed GHP system also can implemented in cold environments so that it can be used to heat residential and commercial buildings in the winter and cool it in the summer season.

Table 5. Financial of Geothermal System and Compared to HVAC

$\begin{array}{lrr}\text { Annual Costs (\$) } & \text { Geothermal } & \text { Air-cooled Chiller } \\ \text { Boiler }\end{array}$

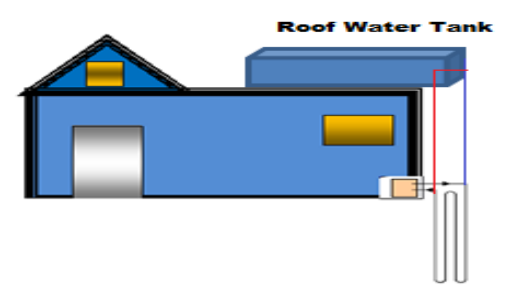

Fig.13. Cooling Desert Roof Water Tank System by GHP

\section{ARTIFICIAL INTELLIGENT AND BIG DATA MACHINE LEARNING ALGORITHM}

\section{A. Big Data and Machine Learning}

In this section artificial intelligent and big data machine learning is used to analyze the weather conditions related to the geothermal heat pump performance such as: the air temperature, sand temperature, solar radiation, day, week, month and the year of recording. Geothermal heat pump big data tall arrays consists of a very huge number of rows (thermal observations) compared to a few number of columns (variables such as temperature, thermal radiation, day, week, etc.). In particular, tall arrays are used to analyze the big data. Tall arrays have the advantage to execute several calculations on diverse types of data that is outof-memory which happened when having large data that cannot be read into computer or system memory. Big data represented in tall arrays and tabulated matrices that have any number of rows can be used to perform out-ofmemory data calculations. Another feature of the tall arrays typically is that they can be kept unevaluated until calculations are requested to be performed.

Moreover, deferred calculations helps to combine the queued calculations by executing the minimum passes through the big data which will save time and calculate the output request when necessary.

Geothermal heat pump and weather parameters data store can be created and enable a collection an arbitrarily large amounts of data. Even missing data can be dealt with and replaced by a non-available data $(\mathrm{NaN})$.Variables of concerned can be selected and categorized such as controlled temperature, room number, heat pump unit number and so on.

Additionally, geothermal tall data arrays can deal with any type of data such as numeric, logics, day, time duration, location or strings. Another significant feature of big data tall arrays is that it is not necessary to execute all or the majority of calculations immediately. On the contrast, actual calculations can be postponed until a computation request output is made. This will enable to keep tracking of all calculations and optimize the number of operational passes through the big data and will save time.

Data can also be sorted to view the top maximum or top minimum in switching-off controlled temperatures. Instead of plotting every single point in a big data set of the geothermal heat pump system, big data tall arrays can be visualized by minimizing the number of data points using sampling.

The proposed artificial machine learning algorithm can be used to perform diverse calculations depends on data types using tall arrays and tables despite the number of rows. Out-of-memory data can be analyzed in a way that tall arrays can be called for evaluation based on the request with a minimum number of passes and time execution. The following details summarizes the technique.

\section{B. Artificial Intelligent Big Data Analysis Criteria}

The proposed artificial machine learning criteria can be implemented using the following algorithm:

Step 1: Collect the geothermal dataset and create data storage. Identify the variables.

Step 2: Create Tall Arrays and Tall Tables that contain dates, numeric values of the geothermal dataset.

Step 3: Initiate and perform calculations on the tall data arrays.

Step 4: Gather the results. Defer unneeded operations. 
Optimize number of calculations passes.

Step 5: Index and subscript of Tall Arrays. Select data subset.

Step 6: Choose data by logic indexing

Step 7: Identify Biggest Switch-off Cooling Hours

Step 8: Present the results in charts

Step 9: Scale-up the subset data to the whole dataset

Step 10: Partition geothermal data into training set and validation Set.

Step 11: Perform predictive analytics of switch-off cooling control using machine learning supervised learning model. Validate Model.

\section{AI AND BIG DATA MACHINE LEARNING OF DESERT GTH: SMART SYSTEM FOR UAE APPLICATION}

\section{A. Dataset and System Size}

For the purpose of analysis in this research, the mean switch-off control hours of the geothermal heat pump is analyzed. This can be implemented by gathering all switch-off control hours and bring the results into memory which may require one single pass through the data operations. The weather historic records has been collected from Weather Underground website which provides weather reports and data for worldwide locations worldwide including UAE cities including $\mathrm{Al}$ Ain City and other weather stations.

This data set characterizes the daily temperature records since May $1^{\text {st, }} 2015$ until May $25^{\text {th }}$, 2018. This represents a data size of $1120 \times 2$ of the date and corresponding average daily temperature (total of 2240 data size). A sample data of January $1^{\text {st }}-10^{\text {th }}, 2016$ records is shown in the Table 6 below.

Some data can also be indexed by displaying only the first and last lots of the geothermal system tall array such as the first 1000 rows instead of the entire data. Logical operations on tall arrays can be also used to identify if true or false. Some rooms served by the geothermal heat pump system can also be selected for example by assigning the variable Room to the value 'Living Room'.

Table 6. Sample No. 1 of the Al Ain, AD Weather Conditions

\begin{tabular}{|c|c|}
\hline Date & Average Temperature, ${ }^{\circ} \mathbf{C}$ \\
\hline $1 / 1 / 2016$ & 24 \\
\hline $1 / 2 / 2016$ & 25 \\
\hline $1 / 3 / 2016$ & 21 \\
\hline $1 / 4 / 2016$ & 19 \\
\hline $1 / 5 / 2016$ & 19 \\
\hline $1 / 6 / 2016$ & 20 \\
\hline $1 / 7 / 2016$ & 19 \\
\hline $1 / 8 / 2016$ & 19 \\
\hline $1 / 9 / 2016$ & 20 \\
\hline $1 / 10 / 2016$ & 21 \\
\hline
\end{tabular}

\section{B. Machine Learning and Big Data Control of GTHP}

In this analysis, the Bosch four ton geothermal heat pump unit is selected as suitable applicable solution [34]. This model provides the required cooling capacity for $\mathrm{Al}$
Ain city with the GTHP compressor and corresponding ground heat exchanger which uses a two stage compressor. This Bosch geothermal heat pump will be operating at a full load most of the cooling run time during the summer time if the temperature exceeds $37^{\circ} \mathrm{C}$ $\left(102^{\circ} \mathrm{F}\right)$ as displayed in Table 7 . If the outdoor temperature drops closer to approximately $24^{\circ} \mathrm{C}$, the Bosch GTHP will begin to return to lower cooling or partial load capacity. Meanwhile, if the temperature drops below $19^{\circ} \mathrm{C}\left(67^{\circ} \mathrm{F}\right)$, then the GTHP will be switched off and save power.

Table 7. 4Ton Bosch Geothermal Heat Pump Unit, Technical Manual, Page 32 [34]

Bosch Geo Solutions Software Data
\begin{tabular}{|c|c|c|c|c|c|c|}
\hline $\begin{array}{c}\text { Bin } \\
\text { ('F) }\end{array}$ & $\begin{array}{c}\text { Bin } \\
\text { Hrs }\end{array}$ & $\begin{array}{c}\text { Bidg Load } \\
\text { (Btuh) }\end{array}$ & $\begin{array}{c}\text { EWT } \\
\text { ('F) }\end{array}$ & $\begin{array}{c}\text { HPCap } \\
\text { (Btuh) }\end{array}$ & $\begin{array}{c}\text { Run } \\
\text { Time }\end{array}$ & $\begin{array}{c}\text { Pwr } \\
\text { (kW) }\end{array}$ \\
\hline 102 & 26 & 45714 & 100 & 45714 & $100 \%$ & 3.60 \\
97 & 228 & 38571 & 95 & 38571 & $100 \%$ & 2.46 \\
92 & 427 & 31429 & 91 & 38235 & $82 \%$ & 2.24 \\
87 & 570 & 24286 & 86 & 38908 & $62 \%$ & 2.15 \\
82 & 852 & 17143 & 82 & 39581 & $43 \%$ & 2.06 \\
77 & 1126 & 10000 & 77 & 40254 & $25 \%$ & 1.98 \\
72 & 899 & 2857 & 73 & 40926 & $7 \%$ & 1.89 \\
67 & 827 & 0 & 67 & & 0 & 0 \\
62 & 701 & 0 & 66 & & 0 & 0 \\
\hline
\end{tabular}

Table 8. Bosch Heat Pump Unit Interpolation of Run Time

\begin{tabular}{|c|c|c|}
\hline $\mathrm{T},{ }^{\circ} \mathrm{C}$ & Switch-Off (Hours) & Switch-On (Hours) \\
\hline 40 & 0 & 24 \\
\hline 39 & 0 & 24 \\
\hline 38 & 0 & 24 \\
\hline 37 & 0 & 24 \\
\hline 36 & 0 & 24 \\
\hline 35 & 1 & 23 \\
\hline 34 & 3 & 21 \\
\hline 33 & 4 & 20 \\
\hline 32 & 7 & 18 \\
\hline 31 & 9 & 15 \\
\hline 30 & 11 & 13 \\
\hline 29 & 12 & 12 \\
\hline 28 & 14 & 10 \\
\hline 27 & 15 & 9 \\
\hline 26 & 17 & 7 \\
\hline 25 & 18 & 6 \\
\hline 24 & 19 & 5 \\
\hline 23 & 21 & 3 \\
\hline 22 & 22 & 2 \\
\hline 21 & 23 & 1 \\
\hline 20 & 24 & 1 \\
\hline 19 & 24 & 0 \\
\hline 18 & 24 & 0 \\
\hline 17 & 24 & 0 \\
\hline 16 & 24 & 0 \\
\hline 15 & 24 & 0 \\
\hline
\end{tabular}

Based on the technical information provided by Bosch 4 Ton Geothermal Heat Pump Unit provided in Table 7, 
an interpolation table is constructed to correlate the GTHP control mode (switch-on/switch-off) and running time with temperature values. Running time of $100 \%$ represents a full 24 hours operation, $25 \%$ running time indicates 6 hours of GTHP operations, meanwhile $0 \%$ represents a full 24 hours switching status. Further details are depicted in Table 8.

Big data machine learning algorithm introduced in section $\mathrm{V}$ has been implemented by creating tall arrays for the $1120 \times 2$ dataset. Preview of partial subset of the first week on January of 2016 is displayed in Table 9 showing year, week, day and geothermal switch off hours which ranges from 18 to 24 hours.

Table 9. Preview of the Geothermal Heat Pump System Big Data

\begin{tabular}{lccc} 
Year & Month & DayofMonth & \multicolumn{2}{c}{ SwitchoffHours } \\
2016 & 1 & 1 & 19 \\
2016 & 1 & 2 & 18 \\
2016 & 1 & 3 & 23 \\
2016 & 1 & 4 & 24 \\
2016 & 1 & 5 & 24 \\
2016 & 1 & 6 & 24 \\
2016 & 1 & 7 & 24
\end{tabular}

In order to achieve efficient out-of-memory calculations, operations can be performed for a subset data and deferred for the rest. A display of the deferred data is shown in Table 10. Moreover, this approach will benefit in saving total time executions and number of data passes. Table 11 demonstrates an average of two passes were achieved so quickly with an average switch hours of 11.77 .

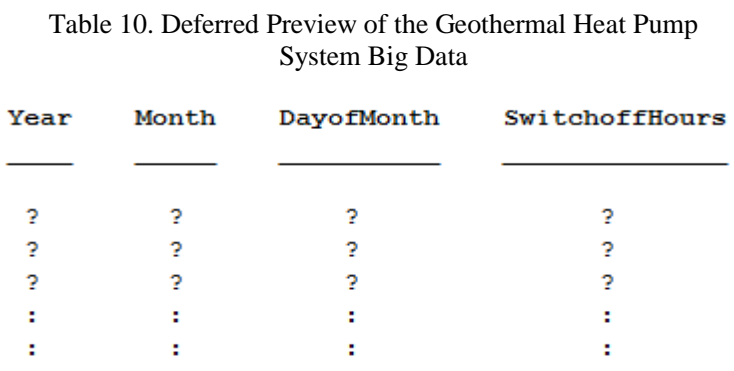

Table 11. Mean of the Switch-off Control Hours of the Geothermal Heat Pump System Big Data

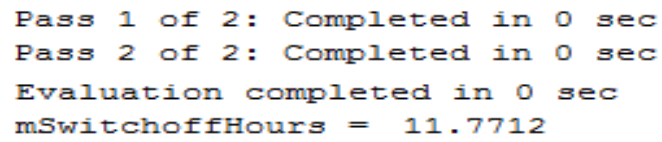

Another machine learning subset has been evaluated for the cooling period starts at May 18th until May 25th, 2018 is demonstrated in Table 12 and Table 15. It is found out that the GTHP is switched off for 11 hours on May 19 of 2018 which represents the maximum idle period, meanwhile, the GTHP operated for 21 hours for the period ranges between 22-25 of May, 2018 with only 3 hours of switching off as displayed in Table 13.
Table 12. Sample No. 2 of the Al Ain, AD Weather Conditions

\begin{tabular}{|c|c|}
\hline Date & Average Temperature, ${ }^{\circ} \mathbf{C}$ \\
\hline $5 / 18 / 2018$ & 32 \\
\hline $5 / 19 / 2018$ & 30 \\
\hline $5 / 20 / 2018$ & 31 \\
\hline $5 / 21 / 2018$ & 32 \\
\hline $5 / 22 / 2018$ & 34 \\
\hline $5 / 23 / 2018$ & 34 \\
\hline $5 / 24 / 2018$ & 34 \\
\hline $5 / 25 / 2018$ & 34 \\
\hline
\end{tabular}

Table 13. Sample Preview of the Geothermal Heat Pump System of January 2018

\begin{tabular}{|c|c|c|c|}
\hline Year & Month & DayofMonth & Swi tchoffHours \\
\hline 2018 & 5 & 18 & 7 \\
\hline 2018 & 5 & 19 & 11 \\
\hline 2018 & 5 & 20 & 9 \\
\hline 2018 & 5 & 21 & 7 \\
\hline 2018 & 5 & 22 & 3 \\
\hline 2018 & 5 & 23 & 3 \\
\hline 2018 & 5 & 24 & 3 \\
\hline 2018 & 5 & 25 & 3 \\
\hline
\end{tabular}

Due to huge geothermal data, it is very important to sort the days when the GTHP has the maximum operating hours and minimum operating hours. This information is crucially important to draw conclusions about the energy consumption and economic saving. It will also provide recommendations about the maintenance schedules either it is routine check or inspection, or preventive maintenance, or troubleshooting or parts repair. For example Table 14 shows the big data analysis shows that geothermal heat pump system is entirely switched off on January 4-7, 2016. This indicates there were full 4 days of bill saving. These days can for example be used to repair or maintain the GTHP components, and/or inspect and check the piping, the wiring. System performance and conditions can be displayed on the control panel, or can be seen on the SCADA or DCS system as well as transmitting this information via smartphones and apps.

Table 14. Preview of the Most Switch-off Hours from 2016

\begin{tabular}{lcccc} 
Year & Month & DayofMonth & \multicolumn{2}{c}{ SwitchoffHours } \\
2016 & 1 & 4 & 24 \\
2016 & 1 & 5 & 24 \\
2016 & 1 & 6 & 24 \\
2016 & 1 & 7 & 24
\end{tabular}

Due to huge and big data it is not suitable to plot all data point, therefore using tall arrays and tall tables can provide a visualized display of the geothermal data over years 2015-2018. The histogram shown in Fig. 14 represents number of switch-off hours of the geothermal heat pump system. This chart is valuable in calculating power consumption cost related to the GTHP system 
operation. Additionally, it will help the maintenance team or service provider to prepare the maintenance schedules and tasks. The difference in the annual columns for year $2015,2016,2017$ and 2018 is due to the availability of data has been obtained from Weather Underground.

Machine learning analysis of big data of geothermal heat pump can also be extended to calculate the average switching-off control hours per month. January represent the most economic month with less operating hours, meanwhile, summer months such as June, July and August bring an expensive bill with more operating hours as shown in Fig. 15.

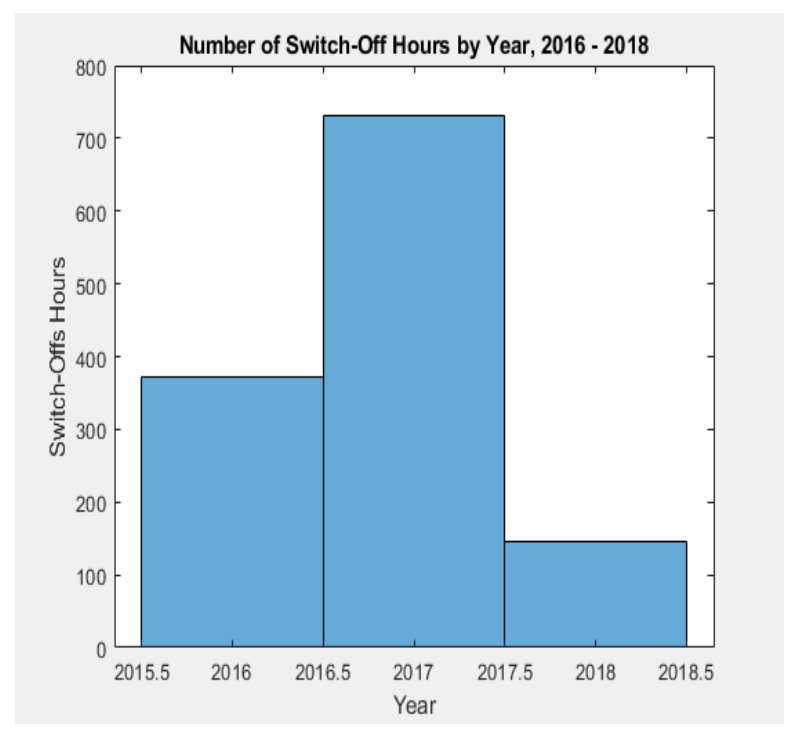

Fig.14. Number of Switch-off Hours of GHP System from Years 2015/18

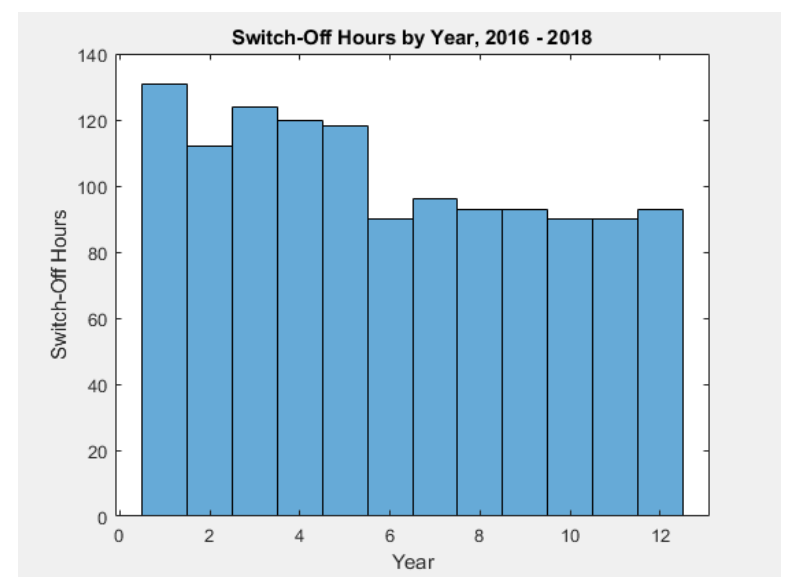

Fig.15. Switch-off Hours of the GHP System per Month for 2015/18

In order to develop the machine learning of the geothermal heat pump system, the data is split into two groups: a training subset and a validation subset by using random sampling and supervised linear regression learning mode. Development and utilization fitted supervised learning model will enable the system to predict the switch-off control hours and make it intelligent and smart. Moreover, it supervise the GTHP controller to switch on and off the system without the necessity to sense and measure real data. In other words, it will predict new operating switch-off-on control hour values and calculate the residuals. Data will be further explored by computing its centrality and the effect of the month and day of the week. The histogram depicted in Fig. 16 demonstrates the predicted trend of daily operating hours on monthly basis for the years 2015-2018. It is noticed that the supervised learning model was successful in predicting and controlling the GTHP operations. The white areas indicates operating hours, meanwhile, the blue areas represents switch-off hours. This will save almost $\$ 553$ per year and $\$ 27,000$ of life cycle cost.

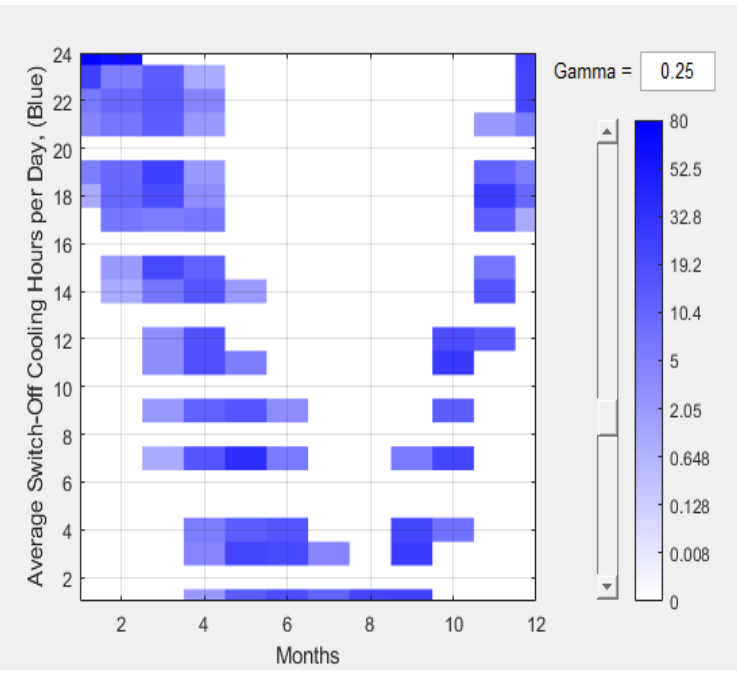

Fig.16. Switch-off Hours Control of the GHP System from per Month for 2015-2018

\section{CONCLUSION}

In this paper a novel artificial intelligent machine learning assisted geothermal heat pump (GHP) is proposed to analyze, design, control and predict its thermal system performance. The advantage of the geothermal source is represented in its sustainability, economic feasibility and availability around the clock. The main goal of this research is to generate a competitive thermal system based on thermodynamics principles. Historic weather conditions recorded by Weather Underground is used to design the GHP for Al Ain city in UAE as the main case study. The results show that geothermal heat pump are considered to be most profitable in meeting cooling needs during summer season and a relatively small heating load during winter.

The horizontal $66 \mathrm{~m}$ trench length layout resulted in cooling specifications of: 2.8 pump COP, flow rate of 30 $\mathrm{L} / \mathrm{min}$ a cooling capacity of $12.4 \mathrm{~kW}$. On the other hand, heating specification led to: 4.3 pump COP, flow rate of $38 \mathrm{~L} / \mathrm{min}$ a cooling capacity of $14.8 \mathrm{~kW}$. The GHP is found to be advantageous by saving almost $80 \%$ annually with an estimated cost of $\$ 1700$ compared to HVAC system. Amazingly, GPH life cycle cost is reduced by $87 \%$ to $\$ 14,700$ with respect to traditional systems. 
Moreover, artificial intelligent and big data machine learning algorithm are used to analyze the weather thermal conditions and GHP performance for 2015-2018 data based tall arrays. Switch-off control hours of the geothermal heat pump is analyzed. One of Bosch four ton geothermal heat pump units is selected as a benchmark for GHP controllability analysis which has a ground heat exchanger and a two stage compressor. Bosch GHP operates at full load if the temperature exceeds $37^{\circ} \mathrm{C}$ and will switch-off if the temperature drops below $19^{\circ} \mathrm{C}$. An interpolation subset has be created as a basis for machine learning. Big data machine learning algorithm introduced in section $\mathrm{V}$ has been implemented by creating tall arrays for the $1120 \times 2$ dataset.

GTHP maximum operating hours and minimum operating hours have been sorted out by big data analysis to provide information about the energy consumption, economic saving, making recommendations about the maintenance schedules either it is routine check or inspection, or preventive maintenance, or troubleshooting or parts repair. For instance, January is figured to be the most economic month with less operating hours. This month can for example be used to repair or maintain the GTHP components, and/or inspect and check the piping, the wiring. Meanwhile, summer months such as June, July and August are found to be very costly.

GHP system has become more intelligent by implementing a supervised linear regression machine learning algorithm in which a training subset and a validation subset are used. It is noticed that the supervised learning model was successful in predicting and controlling the GTHP operations. This led to saving almost $33 \%$ of the annual cost down to $\$ 1,123$ from $\$ 1676$ as well as saving $\$ 27,000$ of life cycle cost.

The achieved saving out of this proposed artificial intelligent machine learning strategy are remarkably found to be more economic and competitive compared to other schemes reported by other researchers. For example [14] has reported saving only $12 \%$ of cooling periods annually. In addition, the work scheme in [22] reported a power reduction of $8.7 \%$.

It recommended that smart apps can be linked to GHP system to report its performance and conditions can be displayed on the control panel, or can be seen on the SCADA or DCS system as well as transmitting this information via smartphones and apps. Moreover, GHP system can be connected with real-time weather radar or station without the need for extensive sensory.

\section{REFERENCES}

[1] Enrico Barbier, "Nature and technology of geothermal energy: A review," Renewable and Sustainable Energy Reviews, Elsevier, Volume 1, Issues 1-2, , Pages 1-69, March-June 1997.

[2] Lund, John W., 1988. "Geothermal Heat Pump Utilization in the United States," Geo-Heat Center Quarterly Bulletin, Vol. 11, No. 1, Klamath Falls, OR.

[3] Bruce D. Green and R. Gerald Nix, Geothermal-The Energy Under Our Feet Geothermal Resource Estimates for the United States, technical report, National Renewable Energy Laboratory, Colorado, 2006.
[4] Alyssa Kagel, Diana Bates, \& Karl Gawell, A Guide to Geothermal Energy and the Environment, Geothermal Energy Association, 2006.

[5] San Diego Regional Renewable Energy Study Group, Chapter 5: Potential for Renewable Energy in the San Diego Region, The Center for Energy Efficiency \& Renewable Technologies, April 7, 2005.

[6] Liz Battocletti, Geothermal Small Business Workbook, Bob Lawrence \& Associates, Inc., U.S. Department of Energy, Office of Energy Efficiency and Renewable Energy, Geothermal Technologies Program, May 2003.

[7] John Sass and Sue Priest, Geothermal California, U.S. Geothermal Development, October/September 2002.

[8] McQuay International, Geothermal Heat Pump Design Manual, Application Guide AG 31-008, 2002.

[9] Masashi Shibaki, Fredric Beck, Geothermal Energy for Electric Power A REPP Issue Brief, Renewable Energy Policy Project, December 2003.

[10] Y. A. Cengel, M. A. Boles, Thermodynamics: an Engineering Approach, Fifth Edition, McGraw Hill, 2006.

[11] Silvia Cocchi, Sonia Castellucci, and Andrea Tucci, Modeling of an Air Conditioning System with Geothermal Heat Pump for a Residential Building, Mathematical Problems in Engineering, Volume 2013, Article ID 781231, 6 pages, Hindawi Publishing Corporation, 2013.

[12] M. Fathizadeh, Daniel Seim, Design and Implementation of Geothermal Systems for Heating and Air Conditioning, Proceedings of the World Congress on Engineering and Computer Science 2013, Vol I (WCECS 2013), San Francisco, USA, 23-25 October, 2013.

[13] Gaffar G. Momin, Experimental Investigation Of Geothermal Air Conditioning, American Journal of Engineering Research (AJER), Volume-02, Issue-12, pp157-170, 2013.

[14] K. S. Leea, E. C. Kangb, , M. Ghorabc, L. Yangc, E. Entchevc, E. J. Leea, Smart Building Heating, Cooling and Power Generation with Solar Geothermal Combined Heat Pump System, 12th IEA Heat Pump Conference 2017, Roterdam, Holland, 2017.

[15] Sneha Shahare, T. Harinarayana, Energy Efficient Air Conditioning System Using Geothermal Cooling-Solar Heating in Gujarat, India, Journal of Power and Energy Engineering, 4, 57-71, 2016.

[16] Jaai Prakash Badgujar, Dheeraj Dilip Kulkarni, Sharique Ali Ahmad, Fauzia Siddiqui, Paramjit Thakur, Ground Coupled Heat Exchanger Air Conditioning System: Case Study, International Journal of Scientific \& Engineering Research, Volume 8, Issue 3, March-2017.

[17] Manan Shah, Anirbid Sircar, Karan Patel, Nahid Shaikh, Vivek Thakar, Dwijen Vaidya, Shishir Chandra, Comprehinsive Study on Hybrid Geothermal-Solar Cooling Systems with Special Focus on Gujarar, Western India, 43rd Proceeding on Workshop on Geothermal Reservoir Engineering, Stanford University, February 1214, 2018.

[18] Sanjay N. Mali, Ashok B. More, D. S. patil, Application of Geothermal Cooling Techniques to Improve Thermal Conditions of a Residential Building, International Journal of Civil and Structural Engineering Research, Vol. 2, Issue 1, pp: (158-161), 2014.

[19] Nimish Dhepe, Raahul Krishna, A Review of the Advancements in Geothermal Heating and Cooling System, Journal of Alternate Energy Sources and Technologies, Volume 8, Issue 1, 2018.

[20] Rahul Vadher, Hiren Prajapati, Geothermal Air Conditioning, International Journal of Engineering Sciences \& Resrarch Technology, 4(10): October, 2015. 
[21] Seyed Houman Razavi, R. Ahmadi, and Alireza Zahedi, Modeling, Simulation and Dynamic Control of Solar Assisted Ground Source Heat Pump to Provide Heating Load and DHW, Applied Thermal Engineering Journal, Elsevier, Volume 129, Pages 127-144, 25 January 2018.

[22] Elisa Moretti, Emanuele Bonamente, Cinzia Buratti and Franco Cotana, Development of Innovative Heating and Cooling Systems Using Renewable Energy Sources for Non-Residential Buildings, Energies Journal, 6, 51145129, 2013.

[23] Alexandra L'Heureux, Katarina Grolinger, Hany F. ElYamany, Miriam A. M. Capretz, Machine Learning with Big Data: Challenges and Approaches, IEEE Access Journal, Vol. 5, 2017.

[24] Abdelladim Hadioui, Nour-eddine El Faddouli, Yassine Benjelloun Touimi, and Samir Bennani, Machine Learning Based On Big Data: Extraction of Massive Educational Knowledge, International Journal of Emerging Technologies in Learning (iJET), Vol. 12, No. 11, 2017.

[25] Mehdi Gheisari, Guojun Wang, Md Zakirul cience and Engineering (CSE) and IEEE Int. Conf. on Embedded and Ubiquitous Computing (EUC), Guangzhou, China, 2017.

[26] D. Saidulu, Machine Learning and Statistical Approaches for Big Data: Issues, Challenges and Research Directions, International Journal Alam Bhuiyan, A Survey on Deep Learning in Big Data, IEEE International Conference on Computational Soft Applied Engineering Research ISSN 0973-4562 Volume 12, pp. 11691-11699, Number 21, 2017.

[27] Junfei Qiu, Qihui Wu, Guoru Ding, Yuhua Xu and Shuo Feng, A survey of machine learning for big data Processing, EURASIP Journal on Advances in Signal Processing, 2016.

[28] Dezhi Fang and Duen Horng Chau, M3: Scaling Up Machine Learning via Memory Mapping, ACM SIGMOD/PODS, San Francisco, CA, USA, 2016.

[29] Chandrima Roy, Siddharth Rautaray, and Manjusha Pandey, Big Data Optimization Techniques: A Survey, I.J. Information Eng. and Electronic Business, 4, 41-48, MECS, 2018.

[30] Abdur Rahman, M.N.A. Khan, An Assessment of Data Mining Based CRM Techniques for Enhancing Profitability, I.J. Education and Management Engineering, 2, 30-40, 2017.

[31] Soroush Rezvanbehbahani, Leigh A. Stearns, Amir Kadivar, J. Doug Walker, C. J. van der Veen. Predicting the Geothermal Heat Flux in Greenland: A Machine Learning Approach. Geophysical Research Letters, 2017.

[32] Guo, Yabin \& Wang, Jiangyu \& Chen, Huanxin \& Li, Guannan \& Liu, Jiangyan \& Xu, Chengliang \& Huang, Ronggeng \& Huang, Yao. "Machine learning-based thermal response time ahead energy demand prediction for building heating systems, Applied Energy, Elsevier, vol. 221(C), pages 16-27, 2018.

[33] Romana Markovic1, Caroline Lorz1, Jerome Frisch, Christoph van Treeck, Application of Support Vector Machines for Predicting the Performance of Air-Source Domestic Hot Water Heat Pump Systems, Building Simulation Proceedings of the 15th IBPSA Conference, San Francisco, CA, USA, Aug. 7-9, 2017.

[34] Bosch Thermotechnology Corp., Bosch Geothermal Heat Pumps for Residential Applications, Manual, 2013.

\section{Authors' Profiles}

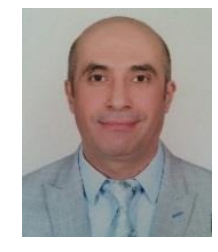

Dr. Murad Al Shibli, Associate Professor, has completed his Ph.D. in 2006 from Concordia University in Canada. Works as the Head of Autonomous Systems Engineering Technology at Abu Dhabi Polytechnic in UAE as well as the Project Manager of Joint Aviation Command Program. Holds more than 25 years of industrial and academic experience in Canada, Jordan and UAE, at Concordia University, German Jordanian University, American University of Sharjah, UAEU University, and Abu Dhabi Polytechnic affiliated with Institute of Applied Technology. Established several new programs in AI, Autonomous Systems, Electromechanical Engineering Technology and Mechatronics Systems at several universities. Worked as the chair of the Mechatronics Program at German Jordanian University. Published more than 50 publications in international journals and conferences. Registered 6 provisional patents in USA. Active researcher in artificial intelligent systems, neural networks, machine learning and big data, robotics, autonomous systems, drones, control systems, mechatronics, control and space systems, and technical education paradigm. Member of IEEE, AIAA, ISA, NASA-TELCOM-ROBEXS, ICREPQ, Round Table Group, and Autonomous Canada.

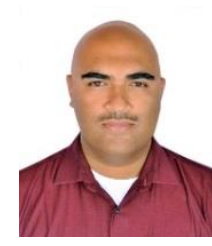

Dr. Bobby Mathew, Assistant Professor, joined UAEU in 2016 as an Assistant Professor. He was awarded PhD in 2011 from Louisiana Tech University, USA. After receiving $\mathrm{PhD}$ he worked at Louisiana Tech University, USA for about two and half years initially as a postdoctoral research associate and later as a Visiting Assistant Professor. Afterwards he worked at Khalifa University in Abu Dhabi as a postdoctoral research fellow for about two years and prior to joining UAEU he worked shortly at New York University (NYUAD) campus in Abu Dhabi, UAE as a research associate. His teaching and research interests are in thermos-fluids, MEMS, microfluidics, and microfabrication and has published extensively in these areas; a co-author on $25+$ journal, $35+$ conference publications, and 2 book chapters.

How to cite this paper: Murad Al Shibli, Bobby Mathew, "Artificial Intelligent Machine Learning and Big Data Mining of Desert Geothermal Heat Pump: Analysis, Design and Control", International Journal of Intelligent Systems and Applications(IJISA), Vol.11, No.4, pp.1-13, 2019. DOI: 10.5815/ijisa.2019.04.01 